\title{
Analysis on Academic Benchmark Design and Teaching Method Improvement under Artificial Intelligence Robot Technology
}

\author{
https://doi.org/10.3991/ijet.v16i05.20295 \\ Xiaojuan Cao $(\varpi)$ \\ Hunan Mechanical and Electrical Polytechnic, Changsha, China \\ caoxiaojuan2020@163.com \\ Zheng $\mathrm{Li}$ \\ Hunan Post and Telecommunication College, Changsha, China \\ Ruyi Zhang \\ Hunan Aerospace Yuanwang Science \& Technology Co., Ltd., \\ Changsha, China
}

\begin{abstract}
To let robots in the education field better implement teaching tasks, the curriculum standards for information technology teaching is designed based on artificial intelligence robot technology. First, based on the robot education, the Lego robot (LEGO MINDSTORMS EV3) for the development and adoption of teaching resources in information technology courses is introduced. Then, according to the sensor teaching in robot education, the teaching contents for the information technology course are designed. The teaching method for the information technology course is improved based on sensor teaching. Finally, the feasibility of the existing teaching resources is evaluated, and the effect of information technology teaching is analyzed through a questionnaire survey. The results show that more than $80 \%$ of students are interested in robot teaching, and more than $70 \%$ of students can master relevant theoretical knowledge in practical operations. It is verified that robot education can arouse students' interest in information technology courses. The learning methods proposed can enable students to better master relevant theories, and it can improve students' operational ability and innovation ability. This work provides basic theories and important references for the adoption of artificial intelligence robotics in education.
\end{abstract}

Keywords-Artificial intelligence; robot education; curriculum standard design; educational teaching methods

\section{Introduction}

The advancement of modernization has produced various advanced technologies. In recent years, artificial intelligence has shined in all walks of life [1]. The basic goal 
of the education field is to cultivate high-quality talents. Under the influence of artificial intelligence, its development model has gradually moved from depending on network and information to depending on intelligence. Artificial intelligence robot technology combines a variety of advanced technologies, and its adoption in education is becoming more and more extensive [2]. At present, robot education still has some problems, its teaching resources are relatively scarce, the teaching goals are not clear enough, and the teaching methods are relatively simple, which have a very negative impact on the teaching effect.

For robot education under artificial intelligence, many foreign and domestic studies were carried out. Some scholars applied robots to the education of some special populations. It was found that robot education helped people with disabilities and students with autism well [3]. Some scholars integrated teaching resources via advanced modern technology, which made robot education more comprehensive and cross-subjects [4]. The adoption and research of robot education abroad are relatively advanced. There are many schools that allow students to learn in practice, and self-programming and debugging of robots improves students' operational ability and learning interest [5]. The research on robot education in China mainly focuses on its combinations with innovative classrooms and micro-classes [6]. Some scholars combined STEM theory with teaching practice to form a novel robot teaching model [7]. In addition, some scholars integrated maker education with robot teaching. As a result, they created an innovative teaching model in Normal College [8]. It can be inferred that there are many practical adoptions of robot education, but there are limited researches on the curriculum standard design in robot education.

In summary, the teaching resources and contents of information technology courses are developed and designed based on artificial intelligence robot technology, so as to improve the teaching methods. Then, the effect of robot education and teaching is evaluated. This study provides an important reference for the adoption of artificial intelligence robot technology in curriculum standard design and teaching method innovation.

\section{Method}

\subsection{Basic theories of curriculum standard design based on robot education}

Artificial intelligence robot technology combines artificial intelligence to program the machine to construct a robot that completes the target operation. Robot education is the adoption of various advanced technologies such as artificial intelligence, mechanical manufacturing, computer technology, and electronic sensors in education and teaching, to cultivate students' hands-on ability and learning interest [9]. Applying robot education can enable students to have a deep understanding of various functions of the robot. Then, through self-programming and robot construction, the scientific literacy and innovation ability of the students are improved.

Robot education has a clear teaching goal. First, it teaches students the theoretical knowledge about the functions, organization, and significance of robots, so as to raise 
students' interest in robot technology [10]. Then, it teaches students to write the operating program of the robot, so that students can independently design and develop software. Such a way can also improve students' ability to analyze and solve problems such as logical thinking. Another goal is to cultivate students' hands-on ability and their innovative ability. To achieve which, students need to build and assemble robots themselves, and divert their thinking to complete various tasks. The overall teaching goal of robot education is based on long-term teaching, so robot teaching during different time period also has different teaching goals. Each stage of teaching has certain teaching difficulties, so the teaching resources and teaching methods need to be adjusted accordingly, which highlights the practicality and comprehensiveness of robot education.

Curriculum standard generally includes the nature of the curriculum, the purpose of the curriculum teaching, the resources of the curriculum teaching, the contents of the curriculum teaching, and the recommendations for teaching implementation [11]. The development of information technology courses enriches the teaching purposes. According to the standards stimulated by the country, for the curriculum standard of information technology, the robot education mainly includes the robot's functional results and production design [12]. The core is the design and manufacture of robots. Students coordinate computer software and hardware, perform macro-control on design and planning, and adopt various advanced technologies to implement robot running tasks. Curriculum teaching resources need to be developed and designed according to the teaching purpose, and the teaching contents also need to be planned. Then, the teaching method needs to be improved according to the teaching contents. Finally, the teaching effect is evaluated, so that corresponding suggestions for the implementation of the teaching can be given.

\subsection{Development of teaching resources of information technology courses based on robot education}

The development of teaching resources has certain principles. The first is the teaching nature of teaching resources. The development of teaching resources requires certain teaching concepts as support, then, the design of teaching purposes and contents can be carried out. The second is that the teaching resources should be scientific, which means the content reflected in teaching resources must conform to the principles of scientific practice [13]. Teaching resources should also be innovative, and teaching must closely follow the trend of the times and conform to the trend of innovation and development. The teaching contents are supposed to cultivate students' innovative thinking and ability. Finally, teaching resources need to be open and available. Open teaching resources can adapt to multiple modes of teaching and also facilitate the integration and utilization of resources.

In this work, Lego EV3 is adopted to develop teaching resources. The LEGO company in the United States has developed a variety of robot products, and the EV3 robot is the third-generation product developed by its R\&D team [14]. Compared with the previous two generations, it has applied various cutting-edge technologies, and the opinions of experts in robot field were adopted for its development. Therefore, there 
has been a great improvement in various functional indicators. The EV3 robot has an extremely complex structure, and can complete various operations. For students, the EV3 robot, as a novelty, can arouse their interest in exploration, which helps to realize the first goal of robot education. The EV3 robot is increasingly adopted in primary and secondary education in China, which promotes the transformation of educational concepts and the improvement of teaching models.

To develop teaching resources for information technology courses based on robot education, LEGO MINDSTORMS Edu EV3 is applied. LEGO MINDSTORMS Edu EV3 is a visual editing software. The operation is relatively simple, and it is easy to get used to it. It is also convenient for public, and suitable for students to operate and learn [15]. LEGO MINDSTORMS Edu EV3 has more powerful functions and a clear and rich design interface. According to the preparation of the corresponding program, the robot can be controlled to perform various complex operations and meet the requirements of the task. The basic principles of its usage and design are shown in Figure 1 .

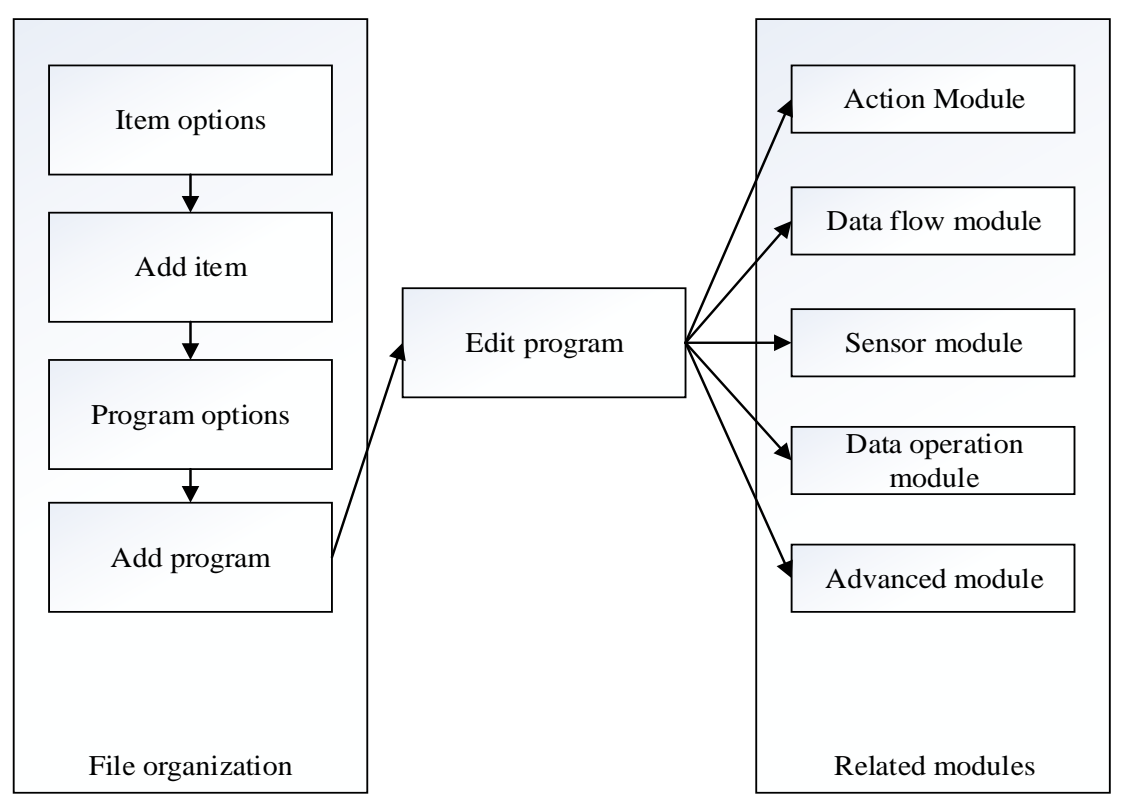

Fig. 1. The design process of LEGO MINDSTORMS Edu EV3

Figure 1 reveals that to design a robot, first, it needs to create a corresponding project. For the functional requirements of the robot, it also needs to create a corresponding project. Then, the corresponding modules of these projects are programed and designed, and the programs are written. Finally, the robot that one designs according to his needs is obtained. The action module in related modules contains various actions in the control program. The data flow module controls the data processing of the program. The sensor module inputs various sensory information of the outside world through the sensor to help program to read, so that the robot can recognize corre- 
sponding feelings. The data calculation module reads, writes, compares, and calculates variables. Advanced module manages related files, Bluetooth, and other advanced functions.

In terms of hardware technology, LEGO MINDSTORMS EV3 has more powerful performance, and has been upgraded accordingly in different aspects. First, an APP is created on a terminal device that can connect via $\mathrm{WiFi}$, which supports various client system operations. To realize better communication between humans and robots, microphones and speakers are upgraded. The interaction is improved, so that the control mode is enhanced. From the initial program control to APP control, the direct command control mode is supplemented to make the robot more intelligent. Then, the LEGO MINDSTORMS EV3 processor is upgraded to increase its memory configuration, thereby increasing the running speed of it. LEGO MINDSTORMS EV3 has 550 technical components at least, and the application personnel can also purchase the corresponding components to install themselves, which makes LEGO MINDSTORMS EV3 have more functions to realize more operations. The adoption of the sensor has also been improved accordingly. The addition of a new type of sensor based on the original version makes LEGO MINDSTORMS EV3 have more new functions. Learners can build and assemble operations according to the instructions. After they are familiar with it, they can design robots that highlight their personalities according to their own interests. They can also divert their thinking and add other robot products or artificial intelligence equipment to LEGO MINDSTORMS EV3 for innovative design.

\subsection{Design of teaching contents of information technology course based on robot education}

The teaching contents in the information technology courses are designed based on robot education. Sensor teaching is taken as example to design teaching contents. Sensor teaching includes software design and behavioral operation, which requires a combination of hand and brain. The teacher explains the programming knowledge of LEGO MINDSTORMS Edu EV3, and introduces the relevant theory of the sensor to the students. While acquiring theoretical knowledge, students need to design and assemble sensor robots by themselves. Through practical operation, the learning of theoretical knowledge is consolidated. By combining knowledge and practice, students' literacy in all aspects are improved, thereby sensor teaching goals are achieved. Figure 2 illustrates the frame structure of sensor teaching. 


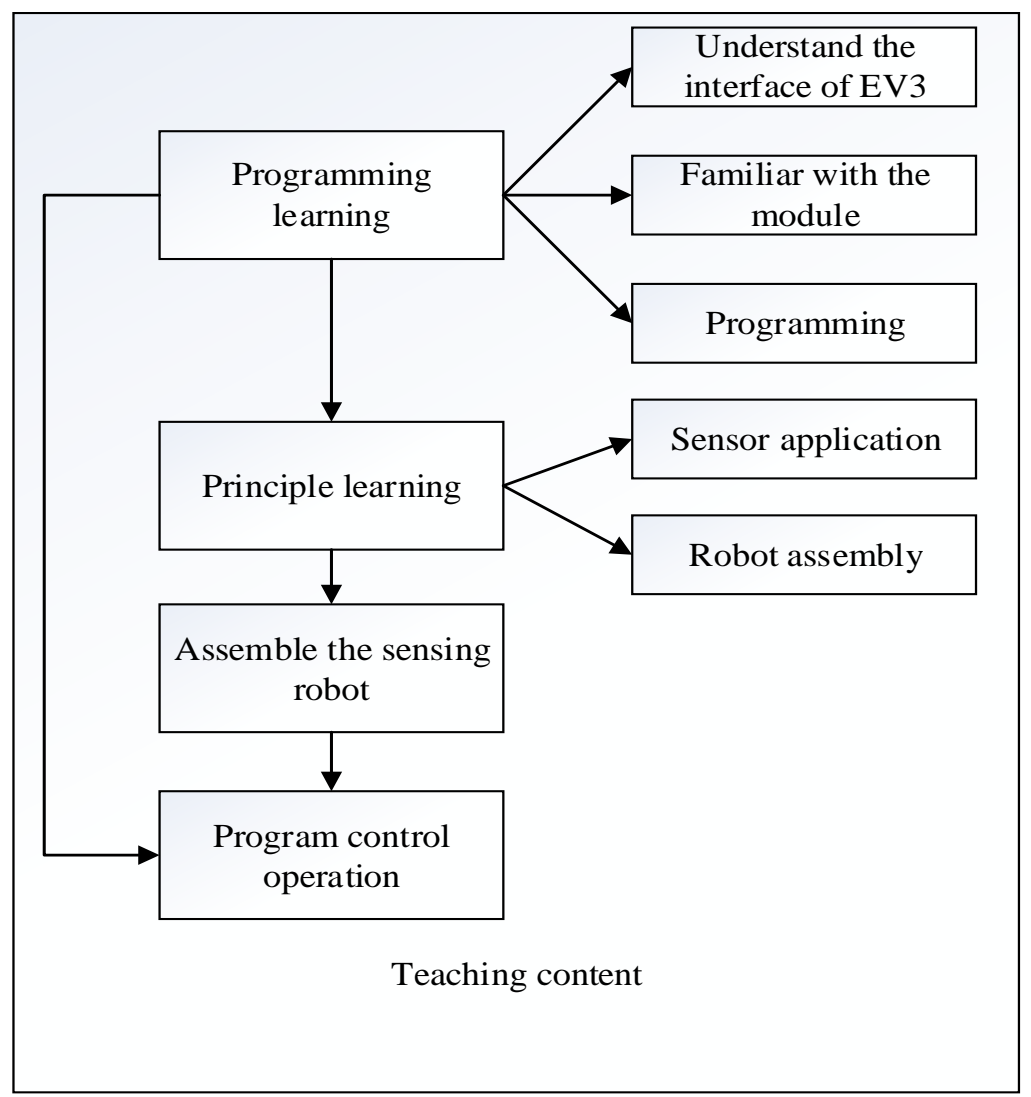

Fig. 2. The content framework of sensor teaching

Figure 2 suggests that the contents of sensor teaching includes LEGO MINDSTORMS Edu EV3 programming learning, adoption principle of sensor learning, robot assembly operation, and programming control robot behavior operation. Students assemble a robot that combines various sensors and employ LEGO MINDSTORMS Edu EV3 for programming, to control the robot's actions and behaviors. To complete the teaching of these contents, the generally applied teaching mode is shown in Figure 3. 


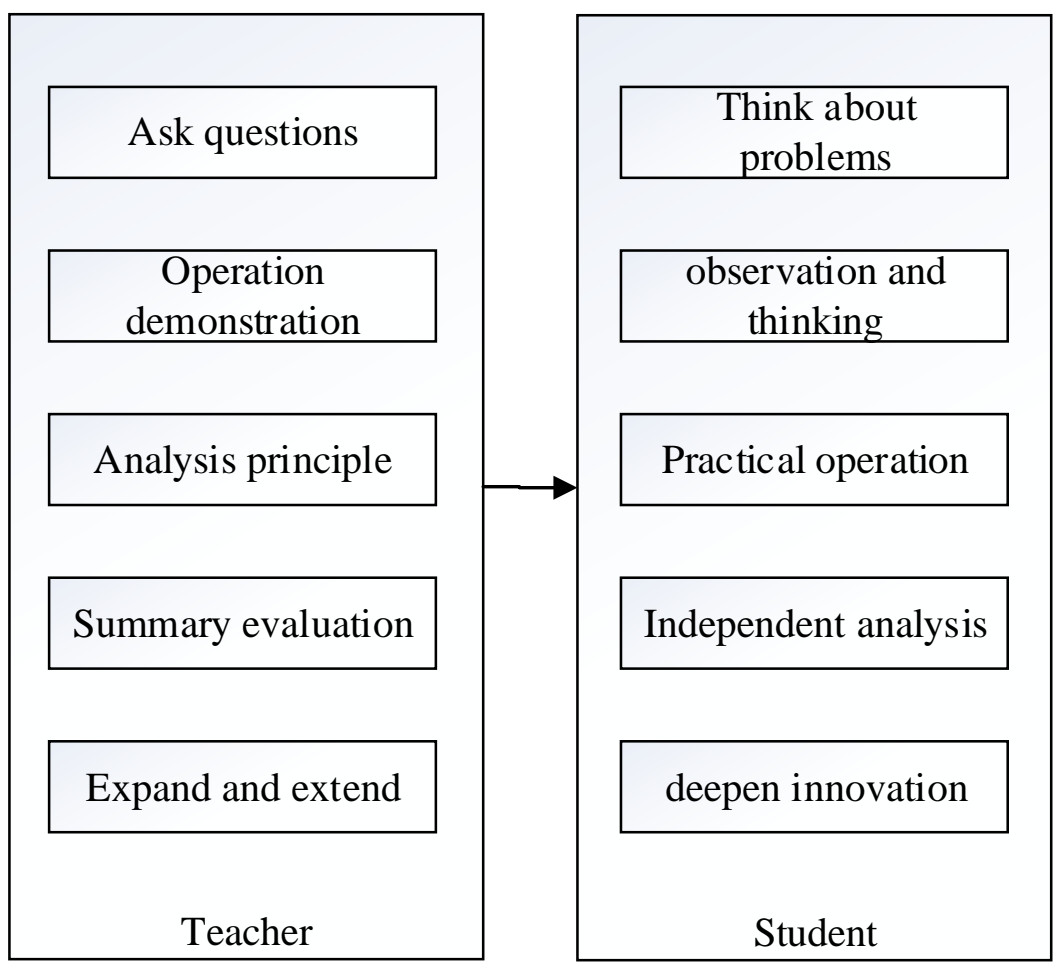

Fig. 3. Sensor teaching mode

From Figure 3, the learning of LEGO MINDSTORMS Edu EV3 is the foundation of the contents learning. To realize the various interfaces in the LEGO MINDSTORMS Edu EV3, and to make students be familiar with the contents and functions of each module, detailed demonstration and explanation are made by the teacher. After the students master the basic theory, they will operate the LEGO MINDSTORMS Edu EV3. During practice, students communicate and cooperate with each other, and constantly think to make innovations. While improving hands-on ability, teamwork ability, computational learning ability, and innovation ability, they can also master relevant theories. Thus, the goal of sensor teaching is effectively achieved.

\subsection{Information technology teaching method based on robot education}

The task-driven method is a relatively perfect teaching method based on the constructivist teaching theory. Robot education has its own unique nature. Task-driven teaching is one of the most common methods. The task-driven method can realize expected teaching effect in the entire robot teaching process [16]. Teachers need to take the overall teaching goals as the basis and divide them into small goals in various stages. The achievement of each small goal will bring students a sense of accomplishment. With the sense of accomplishment, students can give full play to their own 
subjective initiative and complete learning tasks more actively, which will also produce positive effects that students fight for success together. The task-driven method needs to set relevant tasks for students based on the contents of information technology courses. Combined with the characteristics of robot teaching, students' understanding of basic theories and students' learning of basic skills are strengthened. Moreover, according to the students' own situation, the students' qualities and abilities should be cultivated combined with the learning ability, cognitive characteristics, and their own condition.

Inquiry teaching is a typical "learning by doing" teaching method in discovery teaching. When teachers teach students the relevant principles and theoretical knowledge, they will not directly explain it, but give related cases and questions to trigger students to think by themselves. Meantime, students are encouraged to apply various methods to figure it out, including discussion, observation, and experiment. In robot teaching, the cooperative inquiry method is also a relatively common method. Students collaborate to complete the assembly of robots and the design of related products. They can also compete in groups and adopt various communication methods to understand the basic theoretical knowledge.

In this work, based on robot education, the teaching method of information technology is improved referring to task-driven method and inquiry teaching method. The teaching method is shown in Figure 4.

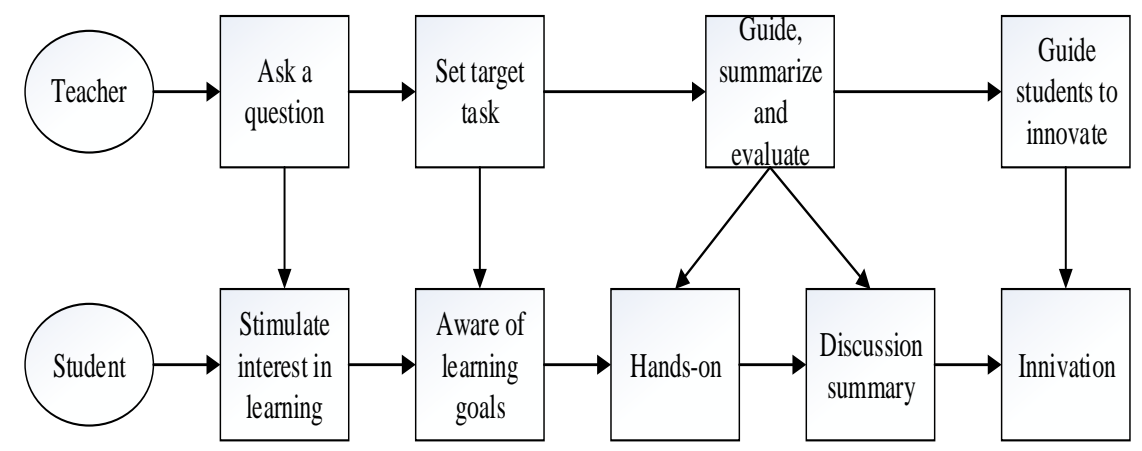

Fig. 4. Teaching method

Figure 4 discloses that teachers first set the relevant context according to the teaching contents. Then, they lead to the research topics of the course, to stimulate students' desire to learn and tap the potential of them. Subsequently, the task-driven method is adopted, which issues small goals continuously, so that the students will continue to explore. The students are divided into several groups to cooperate with each other in practical operations. The teacher is responsible for guidance, who needs to make an in-depth summary of each task, and give a corresponding evaluation of the students' own exploration results. Afterwards, when the teaching goal is realized, the teacher should make corresponding summaries and supplementary explanations. Then, the students summarize the achievements, and manage and consolidate the entire learning process. Finally, the teacher continues to guide students to expand their 
thinking, so that students can carry out independent innovation. In each stage, teachers should pay attention to the learning status of students, and cultivate their hands-on ability, learning ability, innovation ability, and quality in all respects accordingly.

\subsection{Teaching resources and teaching effect evaluation methods}

To comprehensively evaluate the information technology teaching resources, the evaluation index of information technology teaching resources based on robot education is selected, and the corresponding evaluation index system is constructed in Figure 5 .

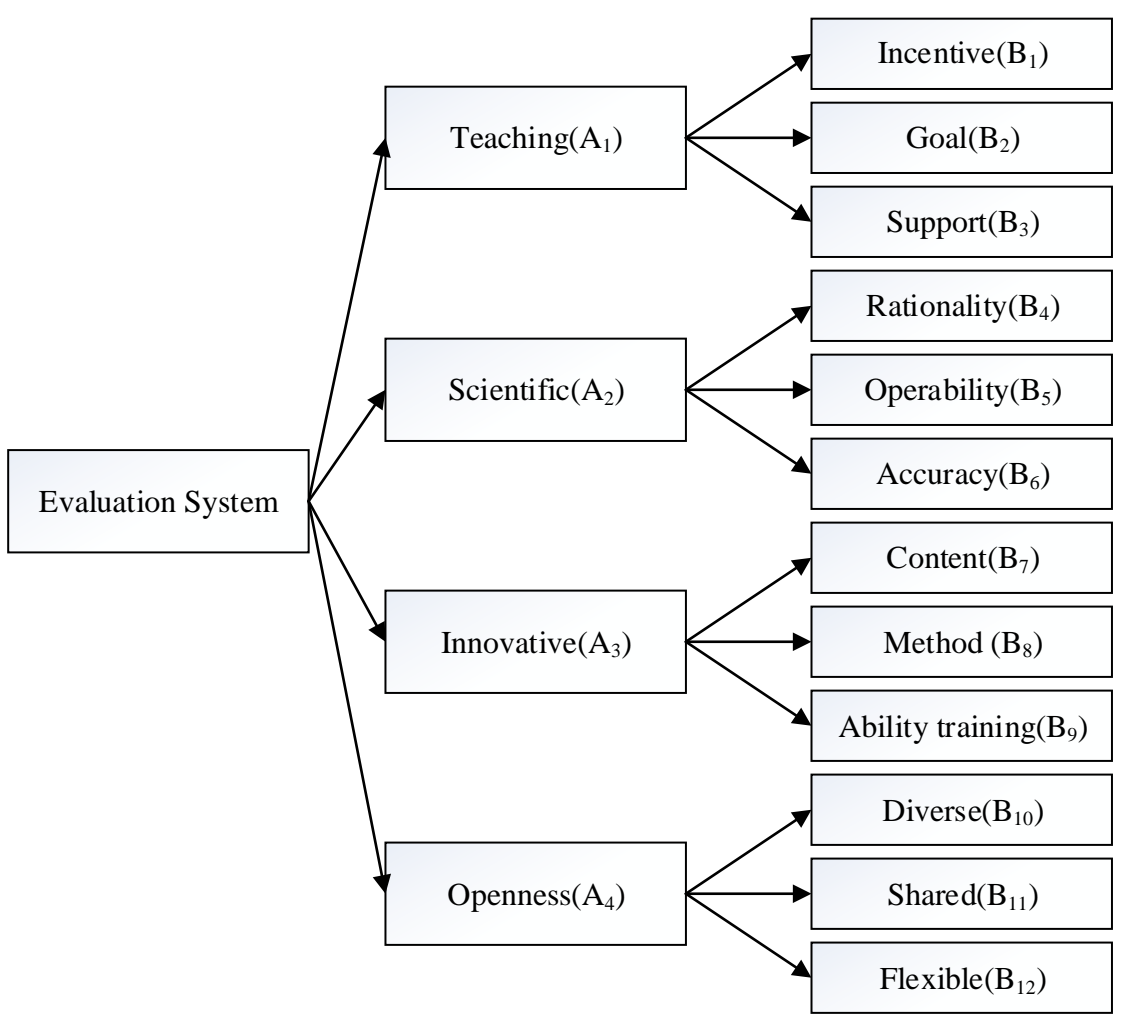

Fig. 5. Evaluation index system for teaching resource

From Figure 5, the evaluation indexes of teaching resources are selected according to the development principles proposed above. To make the evaluation of information technology teaching resources more reasonable, 50 special teachers in robot education field are invited to score the evaluation indexes. The scoring standards are shown in Table 1. 
Table 1. Scoring criteria for evaluation indicators of educational resources

\begin{tabular}{|c|c|c|c|}
\hline First-level indicators & Total score & Secondary indicators & Total score \\
\hline \multirow{3}{*}{$\mathrm{A}_{1}$} & & & 10 \\
\hline & & $\mathrm{B}_{2}$ & 15 \\
\hline & & $\mathrm{B}_{3}$ & 10 \\
\hline \multirow{3}{*}{$\mathrm{A}_{2}$} & \multirow{3}{*}{30} & $\mathrm{~B}_{4}$ & 10 \\
\hline & & $\mathrm{B}_{5}$ & 10 \\
\hline & & $\mathrm{B}_{6}$ & 10 \\
\hline \multirow{3}{*}{$\mathrm{A}_{3}$} & \multirow{3}{*}{20} & $\mathrm{~B}_{7}$ & 5 \\
\hline & & $\mathrm{B}_{8}$ & 10 \\
\hline & & $\mathrm{B}_{9}$ & 5 \\
\hline \multirow{3}{*}{$\mathrm{A}_{4}$} & \multirow{3}{*}{15} & $\mathrm{~B}_{10}$ & 5 \\
\hline & & $\mathrm{B}_{11}$ & 5 \\
\hline & & $\mathrm{B}_{12}$ & 5 \\
\hline
\end{tabular}

To analyze the teaching effect of the information technology curriculum standards and teaching methods, a questionnaire survey is implemented. A total of 50 questionnaires are distributed, and 48 valid questionnaires are finally recovered, with a recovery rate of $96 \%$. The questionnaire survey mainly involves students' attitudes towards the learning of information technology courses based on LEGO MINDSTORMS EV3, their mastery of teaching content, and the cultivation of comprehensive abilities. The form in the Richter scale is adopted to express the items of the questionnaire, and the form and scores are shown in Table 2.

Table 2. Question items and corresponding scores of the questionnaire

\begin{tabular}{|l|c|}
\hline \multicolumn{1}{|c|}{ Problem item } & Score \\
\hline Strongly disagree & 1 \\
\hline Disagree & 2 \\
\hline Uncertain & 3 \\
\hline Agree & 4 \\
\hline Strongly agree & 5 \\
\hline
\end{tabular}

\section{Results and Discussion}

\subsection{Evaluation results of information technology curriculum standard design}

In this work, 4 first-level evaluation indicators of the teaching resources developed by LEGO MINDSTORMS Edu EV3 and 12 second-level indicators are scored. The results are shown in Figure 6. 


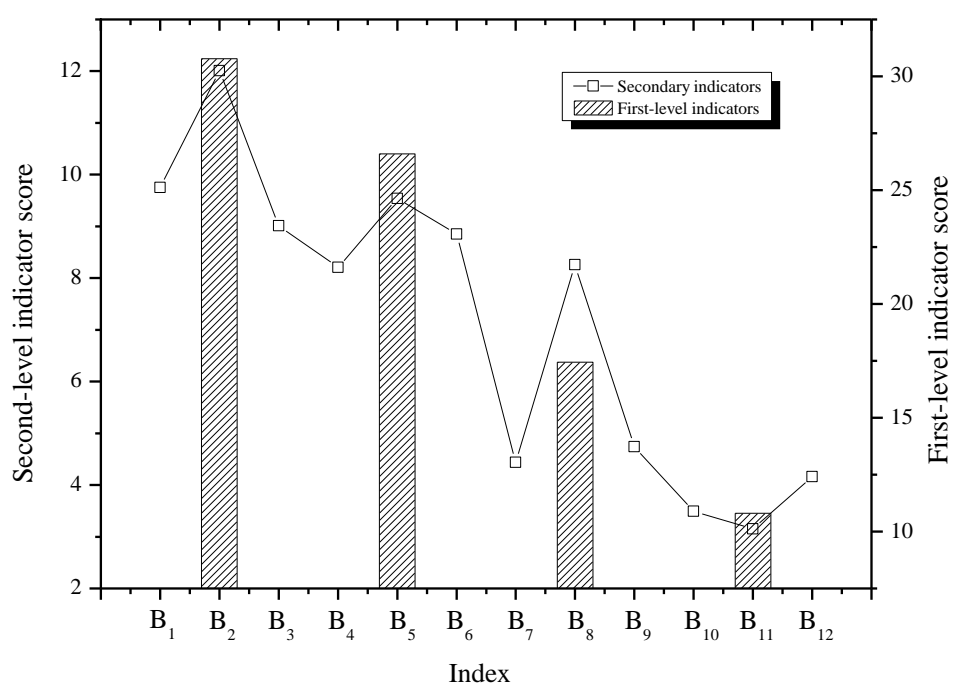

Fig. 6. Teaching resource evaluation results

Figure 6 discloses that the evaluation result of information technology teaching resource proposed in this work is favorable, and the scores of various indicators are relatively high. However, the diversity and openness of teaching resources still need to be strengthened.

\subsection{Analysis of the effect of information technology courses}

Based on the results of the questionnaire survey, the teaching effect of information technology courses based on artificial intelligence robot technology is analyzed. The students' interest in learning and theoretical mastery of sensor teaching content is shown in Figure 7. 


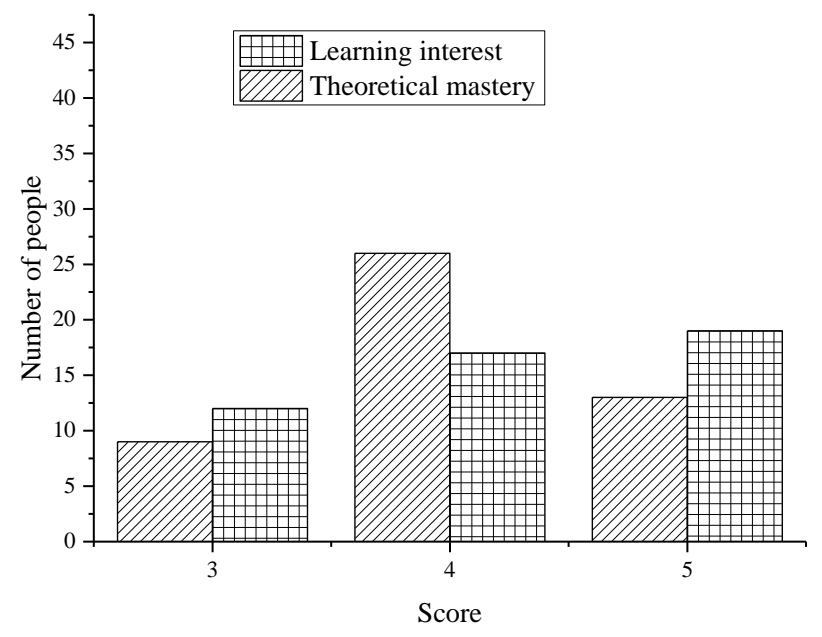

Fig. 7. Students' interest in learning and theoretical mastery

Figure 7 shows that most students are interested in sensor teaching of robot education, which accounts for more than $80 \%$ totally. Besides, more than $70 \%$ of the students have a good grasp of programming knowledge, sensor adoptions, and related theories of robot assembly.

The cultivation condition of students' hands-on operation ability and innovation ability through the questionnaire survey is shown in Figure 8.

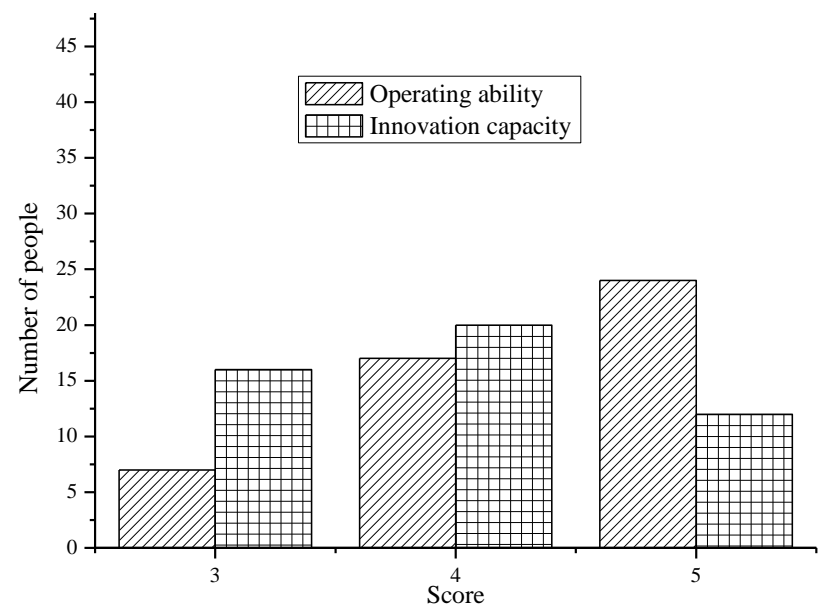

Fig. 8. The improvement of students' hands-on operation ability and innovation ability 
Figure 8 reveals that the teaching method proposed improves the hands-on ability of most students. The teaching method based on robot education has cultivated students' hands-on ability and innovation ability well.

\section{Conclusion}

In order for robot education to complete its teaching goals more successfully and effectively, the curriculum standards of information technology are designed based on artificial intelligence robot technology. LEGO MINDSTORMS Edu EV3 is employed to develop information technology teaching resources. Moreover, information technology teaching content is designed based on sensor teaching, and learning methods are improved. Eventually, the research and development of teaching resources are evaluated and the teaching effect is analyzed. The results show that the teaching resources obtained by the proposed teaching resource development method have been widely recognized in robot education field. The improved teaching methods also realizes ideal teaching effects, which can increase students' enthusiasm for learning. Through the combination of theoretical study and practical operation, students' handson operation ability and innovative ability are cultivated. This work provides an important reference for the adoption of artificial intelligence robot technology in the field of education and teaching, but there are still some deficiencies. The relevant suggestions for curriculum implementation in the curriculum standard design are not comprehensive enough, and relevant research and discussion shall be carried out in the future.

\section{Acknowledgement}

The work was supported by Hunan province vocational college education and teaching reform research project 2019" the profession characteristic distinct higher vocational college communication technology specialized group curriculum system construction research and practice "(number: ZJGB2019157)

\section{References}

[1] Colchester, K, Hagras, H, Alghazzawi, D, et al. (2017). A survey of artificial intelligence techniques employed for adaptive educational systems within e-learning platforms. Journal of Artificial Intelligence and Soft Computing Research,7(1): 47-64. https://doi.org/10.15 15/jaiscr-2017-0004

[2] Laird, J E, Lebiere, C, Rosenbloom, P S. (2017). A standard model of the mind: Toward a common computational framework across artificial intelligence, cognitive science, neuroscience, and robotics. Ai Magazine,38(4): 13-26. https://doi.org/10.1609/aimag.v38 $\underline{\mathrm{i} 4.2744}$ 
[3] Edwards, B I, Cheok, A D. (2018). Why not robot teachers: artificial intelligence for addressing teacher shortage. Applied Artificial Intelligence,32(4): 345-360. https://doi.org/ $\underline{10.1080 / 08839514.2018 .1464286}$

[4] Edwards, C, Edwards, A, Spence, P R, et al. (2018). I, teacher: using artificial intelligence (AI) and social robots in communication and instruction. Communication Education,67(4): 473-480. https://doi.org/10.1080/03634523.2018.1502459

[5] Masters, K. (2019). Artificial intelligence in medical education. Medical Teacher,41(9): 976-980

[6] Lin, P H, Wooders, A, Wang, J T Y, et al. (2018). Artificial intelligence, the missing piece of online education? IEEE Engineering Management Review,46(3): 25-28. https://doi.org/ 10.1109/emr.2018.2868068

[7] Hussin, A A. (2018). Education 4.0 made simple: Ideas for teaching. International Journal of Education and Literacy Studies,6(3): 92-98

[8] Damaševicius, R, Narbutaite, L, Plauska, I, et al. (2017). Advances in the use of educational robots in project-based teaching. TEM Journal,6(2): 342

[9] AlBara Khalifa, Tsuneo Kato, Seiichi Yamamoto. (2019). Learning Effect of Implicit Learning in Joining-in-type Robot-assisted Language Learning System. International Journal of Emerging Technologies in Learning,14(2): 2-19. https://doi.org/10.3991/ijet.v14 $\underline{\mathrm{i} 02.9212}$

[10] Laxmisha Rai. (2018). Offline Support Model for Low Bandwidth Users to Survive in MOOCs. International Journal of Emerging Technologies in Learning,13(10): 270-277. https://doi.org/10.3991/ijet.v13i10.8595

[11] Dali Luo. (2018). Guide Teaching System Based on Artificial Intelligence. International Journal of Emerging Technologies in Learning,13 (8): 90-102

[12] Fabregas, E, Farias, G, Dormido-Canto, S, et al. (2016). Platform for teaching mobile robotics. Journal of Intelligent \& Robotic Systems,81(1): 131-143. https://doi.org/10.1007/ s10846-015-0229-8

[13] Afari, E, Khine, M S. (2017). Robotics as an educational tool: impact of lego mindstorms. International Journal of Information and Education Technology,7(6): 437-442. https://doi. org/10.18178/ijiet.2017.7.6.908

[14] Kim, S W, Lee, Y. (2016). The effect of robot programming education on attitudes towards robots. Indian Journal of Science and Technology,9(24): 1-11

[15] Auerbach, J E, Concordel, A, Kornatowski, P M, et al. (2018). Inquiry-based learning with robogen: An open-source software and hardware platform for robotics and artificial intelligence. IEEE Transactions on Learning Technologies,12(3): 356-369. https://doi.org/ 10.1109/tlt.2018.2833111

[16] Bravo Sánchez, F Á, González Correal, A M, Guerrero, E G. (2017). Interactive drama with robots for teaching non-technical subjects. Journal of Human-Robot Interaction,6(2): 48-69. https://doi.org/10.5898/jhri.6.2.bravo

\section{$7 \quad$ Authors}

Xiaojuan Cao a Chinese university teacher and associate professor. Engaged in the professional teaching work of Hunan Mechanical\&electrical polytechnice, the 
school professional leader, won the title of "national technical expert". The main research direction is electronic information technology and higher vocational education teaching. Email address: caoxiaojuan2020@163.com .

Zheng. Li Engaged in the professional teaching of Hunan Post and Telecommunication college, served as the teaching and research work of Communication Engineering Specialty in Higher Vocational Colleges for 15 years. Zlihunan11231@253.com

Ruyi Zhang, He works in Hunan Aerospace Yuanwang Science\&Technology Co., Ltd. for more than ten years, he has been engaged in special vehicle research. Ruyizhang202012@sina.com

Article submitted 2020-12-04. Resubmitted 2021-01-08. Final acceptance 2021-01-11. Final version published as submitted by the authors. 